\title{
Primera feria buen comienzo Relatorías conversatorio
}

\author{
First meeting "a fair beginning" \\ Discussion session minutes
}

\author{
Gilma Roldan Tabares ${ }^{1}$
}

\begin{abstract}
En el marco de la Primera Feria Buen Comienzo, durante los días jueves 8 y viernes 9 de octubre de 2009, se desarrollan cuatro conversatorios con profesionales y expertos locales y nacionales, en torno al "qué, cómo, con qué y para qué crear ambientes y espacios cálidos para la primera infancia, partiendo de las características particulares de los niños y las niñas y sus múltiples posibilidades de desarrollo.

Cada conversación se diseño para ser desarrollada en 40 minutos, tiempo en el que el público participante tiene la posibilidad de interactuar con el experto y enriquecer los saberes personales y sociales relacionados con la primera infancia.
\end{abstract}

Se presentan algunas relatorías unificadas para los temas de conversación que son comunes a los días jueves y viernes y según el orden en que fueron realizadas.

Para conservar la unidad, el documento aborda unos aspectos básicos que son el nombre del círculo de conversación, título del conversatorio, principales temas tratados, principales ideas intercambiadas en el conversatorio, retos que le presenta al agente educativo, a las instituciones, a la familia, a la ciudad, identificación de los nuevos hallazgos y aportes que encuentran en la propuesta y conclusiones y acuerdos.

Within the framework of the First Meeting "A fair beginning", in October 8-9, 2009, four discussion sessions were held with local and nationwide practitioners and experts, around "what, how, using which means and on which purpose creating warm environments for early childhood, based on little children's specific traits and their manifold development potential.

Licenciada en Dificultades del aprendizaje Escolar. Coordinadora Técnica. Aula taller de Primera Infancia. Contrato interadministrativo Nro 4600020588 de 2009 Secretaria de Educación - Municipio de Medellín - Tecnológico de Antioquia - Institución Universitaria 
Each discussion was designed to be developed in 40 minutes, within which the audience participating had the possibility to interact with the experts, so as to enrich their individual and social learnings related to early childhood.

Several discussion minutes are presented in a unified way sorted by topic, and following the order in which they were held. In order to keep unity, this paper addresses some primary issues, such as the name of the discussion meeting, the title of the discussion session, the main topics addressed, main ideas exchanged during the discussion, challenges posed to educational agents, institutions and families, municipalities, acknowledgement of newly-made findings and contributions for a proposal, conclusions and agreements reached.

Conversatorio: La ciudad de los niños y las nińas.

Moderador: Esteban Escobar Vélez. Concejal de Medellín y Pedro Zapata Pérez. Artista de Medellín.

En este espacio se da la oportunidad para comprender e interpretar el evento que convocó a la ciudad con el objetivo de abrir espacios para niños y nińas, en consecuencia este conversatorio pretende aclarar qué es en realidad una ciudad que piensa en los pequeños.

La ciudad de los niños las nińas, está concebida como un proyecto que convoca a los alcaldes del mundo para escuchar a los menores, por medio de la creación de Consejos de Niños, elegidos por sus pares, quienes diseñando, jugando y reclamando, llevan adelante iniciativas para transformar su propia ciudad.

El ponente especifica los orígenes del proyecto, diciendo que este nació en Fano (Italia), en mayo del 1991 y fue creado e implementado por el italiano Francesco Tolucci, quien desde su inicio ha tenido una motivación política que es trabajar hacia una nueva filosofía de gobierno de la ciudad, tomando a los niños y niñas como parámetro y como garantía de las necesidades de todos los ciudadanos.
La Ciudad de los Niños y las Nińas, busca construir una ciudad diversa y mejor para todos, de manera que los nińos puedan vivir una experiencia como ciudadanos, autónomos y participativos, donde se brinden los espacios para escuchar a los niños y las nińas, y que ellos tomen las decisiones y se vuelvan protagonistas de la ciudad.

En esta perspectiva es necesario adaptar la ciudad a los niños, no los nińos a la ciudad, como se hace actualmente, ofreciendo como propuestas algunos elementos como la autonomía donde los niños deben sentirse libres, dejar de lado la sobreprotección, la participación vista desde la creación del consejo de niños, espacio para ellos, donde puedan desarrollar temas de ciudad, del mismo lado, la seguridad y la participación.

En concordancia con lo expuesto el ponente dice que muchas ciudades del mundo integran la Red de las Ciudades de los Niños y piensan juntas como, con los niños, hacer frente al profundo malestar de las grandes metrópolis, la mercantilización de la vida cotidiana y la ausencia de espacios de juego y convivencia, así como 
construir políticas públicas para la infancia en el territorio, en cada municipio y en cada comuna, en el marco del proyecto Ciudad de los Niños.

En esta propuesta surgen nuevas percepciones como el hecho de concebir a los niños y niñas como los protagonistas, en este caso será una ciudad de derechos; cuando ellos y ellas puedan jugar libre y constantemente, se estará hablando de una ciudad de los niños, sin embargo no es posible concebir una ciudad así, sin el compromiso de sus gobernantes.

Igualmente, se debe pensar y construir una ciudad más verde, donde se pueda patinar y jugar, donde rueden las pelotas. No es hacer una política para la infancia, es que la infancia haga las políticas. A nivel conceptual, es necesario que se comprenda que una ciudad donde el niño está en la calle es una ciudad segura; si es buena para ellos, es buena para todos.

El tema genera algunos retos, el primero es preguntarse por lo que se está creando, lo que se está formando en las mentalidades de los niños y las niñas. Es suplicar por una verdadera educación que permita que jueguen.

En consecuencia el reto para las madres, es darle una mirada a la sobreprotección. Debemos pensar al niño como un océano creador, mirar sus ojos llenos de luz como la posibilidad de recuperar la niñez en medio de esta pesada y de difícil realidad.

Dentro de este contexto surgen algunas preguntas: ¿Cómo debería ser una ciudad que tenga en cuenta a los niños?, ¿Cómo habría qué diseñar y planificar una ciudad a la medida de los pequeños?, ¿Pueden la escuela y el colegio ayudar y favorecer en el aprendizaje de la lectura de la ciudad, y con ello aumentar la autonomía y disminuir la inseguridad?, ¿Qué principios políticos deberían regir las actuaciones de funcionarios y autoridades para que la ciudad permita crecer con seguridad, autonomía y garantía?

Después de estos cuestionamientos los participantes se cuestionan sobre el papel que juegan las instituciones educativas en la propuesta de ciudad y se concluyó que Medellín debe repensar la educación de los maestros, buscando y generando espacios para que se forme una amalgama con los consejos de los niños y que estos logren trasladarse a las aulas de clase.

Como conclusiones finales es necesario entonces, para ser consecuentes con la idea de Tolucci, crear un entorno de ciudad donde la institución tenga un papel fundamental.

Por ello Medellín tiene que pensarse la educación de los maestros y maestras como formadores de sujetos. De igual manera, los padres de familia necesitan una formación, una postura política, una apuesta filosófica para que el compromiso sea realidad. No se trata del mundo de las niñas, se trata del mundo de todos y todas, el mundo de las cosas que se han dejado de decir desde la infancia.

Ante cualquier práctica, desde esa visión compleja de la ciudad, hay que preguntarse por lo qué se es. Si bien el niño es un universo de preguntas, los adultos no son el universo de las respuestas. Esto lleva a dejar que el mundo sea la fuente pura para la infancia. 
Conversación: Familias que aman, bebés que participan: concepciones y prácticas sobre la participación de los niños y niñas durante el primer año de vida.

Moderadores: Isabel Cristina Quiroz, Investigadora Auxiliar, Proyecto CINDE- Génesis, Hernán Restrepo Mesa, Coordinador del Proyecto Fondo de Becas Glen Nimmicht - CINDE.

Para iniciar, se quiso que el auditorio tomara parte y que realmente fuera un conversatorio, fue así como la ponente realiza la siguiente pregunta a los participantes: ¿Qué piensan ustedes de la participación?, los participantes responden que es la oportunidad de hacer algo.

Luego preguntó: ¿Creen ustedes que un niño en su primer año de vida participa?,

Para esta no se escucharon respuestas. La expositora entonces respondió que sí era posible, que ante todo somos seres sociales.

Así mismo, la investigadora del Cinde explicó, a partir de la investigación que realizaron, con 6 familias de vereda Pan de Azúcar del municipio de Sabaneta, que el niño participa desde su misma concepción de desarrollo, lo que hace o deja de hacer. Dijo además, que los adultos siempre están buscando que los nińos los imiten.

Abordó el concepto lineal de desarrollo, en una dirección ascendente, paso por paso. Mencionó que desde que se nace existe un movimiento continuo de factores en desarrollo. Los bebés, por ejemplo, son seres encantados del mundo, les gustan los rostros humanos, que sienten próximos y modifican sus estructuras mentales en contacto con ellos.

Luego habló del reconocimiento de los bebés: "desde que nacemos, hacemos parte de la familia, somos partícipes, incluso desde antes de llegar. Existe una comunicación de los bebés con el mundo y en esta medida se debe fortalecer el vínculo afectivo con ellos".
Hay que reconocer que los niños y niñas son sujetos de derecho y como tales, deben ser incluidos y reconocidos. Desde la gestación, los niños empiezan a influir en su vida y en la vida de los demás. El desarrollo no solamente es un asunto de habilidades y competencias.

Se argumenta que la comunicación con el bebé no comienza cuando se expresa verbalmente, ahí ya ha hecho procesos de comprensión. Son sociales y comunican lo que les agrada o desagrada. Amplían su poder personal, se van sintiendo incluidos y reconocidos, al demandar atención y recibirla.

En sentido más básico, participar significa ser parte, ello implica a su vez, ser reconocido por los otros como parte de, pues es allí donde se logra un lugar desde el cual participar. En el reconocimiento por parte de los otros radica el fundamento de la participación.

En la misma línea de argumentos, los ponentes explican que la familia es el escenario privilegiado para orientar la construcción de ciudadanía, desde las edades más tempranas. Allí se da el principal aprendizaje de las capacidades que cada sujeto tendrá para relacionarse consigo mismo y con otros.

Concluyendo esta parte de la ponencia se dice que como ser pasivo el sólo hecho de existir, de ser, le da una participación. Como ser activo los bebes participan desde el reconocimiento. 
El compartir estas posturas da cuenta del reto que supone para las madres este tema de la participación, el cual las lleva a la necesidad de conocer realmente a sus bebés, identificar lo que quieren, lo que necesitan. El reto es buscar la participación intencionada, entendida como la búsqueda incesante de relacionarse con el otro, de ser partícipe, entender que existe una ciudadanía del niño.

No cabe duda de que los ambientes más favorables a la participación, emergen con mayor fuerza en las familias cuyas concepciones en torno al o la bebé y sus capacidades son más positivas y respetuosas frente a su igual dignidad con el adulto; asimismo donde su existencia ha sido acogida desde el comienzo, con amor.

Es así, como los pensamientos, conocimientos, creencias, imágenes y sentimientos de los integrantes del grupo familiar acerca de la participación de los niños y niñas, son fundamentales en el primer año de vida.

Lo nuevo que se encuentra en esta propuesta es entender que participar es también, una forma de interacción que posibilita la capacidad de influir en la propia vida y en la de otros a partir del reconocimiento que se otorga como persona y de las capacidades presentes y siempre en desarrollo.

El sustento fundamental de un ambiente participativo es el reconocimiento del Otro, en este caso del bebé, lo que conlleva la disposición a observarle, aceptarle y potenciarle en su singularidad. El reconocimiento es la consideración del bebé como persona, como sujeto activo, como apertura; es decir, como otro, tal como lo plantea Gadamer (citado en Melich 1994).

A partir de los aportes de los asistentes, se concluye que existe una insuficiente producción teórica e investigativa en torno a la participación desde el nacimiento. Por lo tanto, es necesario seguir profundizando esta categoría desde una perspectiva incluyente, al igual que otros conceptos relacionados, tales como el reconocimiento, la subjetividad, la ciudadanía y lo político.

Hoy en día sólo participan los que tiene capacidades de hacerlo; es así, como se deben buscar los espacios para permitirle a los niños de primera infancia, que puedan participar

En consecuencia el agente educativo está llamado a diseñar propuestas educativas que promuevan este derecho desde el nacimiento, y contribuyan en la transformación de las concepciones y prácticas culturalmente instaladas que limitan la participación de los niños y las niñas en los ámbitos familiar y comunitario, y que, al mismo tiempo, aporten en la implementación de las políticas.

Conversación: "Tránsito exitoso de los niños y niñas de modalidades educación inicial al entorno escolar".

Moderadoras: Docente. Oliva Herrera Cano. Licenciada en educación especial. Magister en educación. Miembro del laboratorio articulación educativa. Tecnológico de Antioquia.

Docente Gabriela Builes Gil. Licenciada en didáctica del aprendizaje. Magister en psicopedagogía. 
El tema tratado, Tránsito exitoso de los niños y nińas al entorno escolar, es una propuesta en la cual se articula los diferentes entornos familiar, comunitario y escolar, donde mediante un encuentro entre coordinadores y docentes se pretende realizar una reflexión crítica y propositiva respecto al sentido y valor que tiene la transición de los niños y nińas al entorno institucional.

Por esta razón, se hace necesaria la construcción de una propuesta pedagógica con los agentes educativos, que posibilite el tránsito exitoso de los niños y niñas del entorno institucional del Programa Buen Comienzo al entorno escolar en el nivel de transición.

El proceso de formación del niño o niña que permite hacer ese tránsito a la institución escolar, tiene en cuanta algunos aspectos como el personal; en el cual se incluye la autonomía, la identidad y la convivencia, en el aspecto comunicativo están los lenguajes verbales, gráficos y artísticos y finalmente el desarrollo del pensamiento creativo.

Así mismo existen unos aspectos desde los agentes educativos como la resignificación de las experiencias pedagógicas, las prácticas pedagógicas y la investigación.

Por último se hace referencia a lo que le compete a las instituciones educativas como es generar los perfiles educativos, los espacios, la organización del tiempo, la dotación y los recursos para favorecer el tránsito exitoso de los niños y niñas al entorno escolar.

Para hacer posible la materialización de la propuesta se plantean unas herramientas que favorecen este tránsito como la conformación de la comunidad de agentes educativos, la realización de encuentros infantiles, la participación en la red de primera infancia, y la obtención de recursos para la mediación pedagógica.

A partir de esta propuesta se infiere que la pretensión de la misma es involucrar a la comunidad educativa en ese tránsito del niño y la niña al entorno escolar, haciendo que este sea más fácil para éstos, lo que además permite generar en ellos confianza, seguridad y autonomía.

Los aportes y retos que deja el tema tránsito exitoso de los niños y niñas de modalidades de atención al entorno escolar, se sintetizan en la necesidad de desarrollar la creatividad para ofrecer al nińo y niña espacios y estrategias apropiadas para hacerle más fácil el tránsito a las instituciones educativas, además de asumir el compromiso por brindar seguridad y generar en los niños y niñas la autonomía, confianza y seguridad en sí mismos.

Cabe anotar que es responsabilidad de los padres de familia y los docentes hacer el acompañamiento en el proceso de adaptación del niño y niña a su nuevo entorno escolar.

Para concluir es preciso pensar que para hacer exitoso el tránsito de los nińos de modalidades de educación inicial al entorno escolar, se ha de seguir reconociendo al niño y la nińa desde las dimensiones del desarrollo humano (cognitiva, comunicativa, emocional, espiritual, corporal, ética), la formación ha de ser integral.

Para finalizar es importante reconocer que la manera en cómo fue abordado el tema por parte de las ponentes cautivó a los asistentes, generando en éstos motivación y credibilidad en la propuesta. 